\title{
Automatic control system for ion-exchange sorption in industrial production of amino acids as bioprotective factors
}

\author{
Pugacheva Inna \\ Faculty of Ecology and Chemical Technology \\ Voronezh State University of Engineering Technologies \\ Voronezh, Russia \\ eco-inna@yandex.ru
}

\author{
Glotova Irina \\ Faculty of Technology and Merchandizing \\ Voronezh State Agrarian University \\ Voronezh, Russia \\ glotova-irina@yandex.ru
}

\section{Galochkina Nadezhda}

Faculty of Technology and Merchandizing

Voronezh State Agrarian University

Voronezh, Russia

Galochkina.na@mail.ru

\author{
Molokanova Larisa \\ Faculty of Ecology and Chemical Technology \\ Voronezh State University of Engineering Technologies \\ Voronezh, Russia \\ larisa280272@yandex.ru \\ Shakhov Sergey \\ Faculty of food machines \\ Voronezh State University of Engineering Technologies \\ Voronezh, Russia \\ s_shahov@mail.ru

\section{Lobacheva Natalia} \\ Faculty of food machines \\ Voronezh State University of Engineering Technologies \\ Voronezh, Russia \\ naloni@mail.ru
}

\author{
Saranov Igor \\ Faculty of food machines \\ Voronezh State University of Engineering Technologies \\ Voronezh, Russia \\ mr.saranov@mail.ru
}

\begin{abstract}
A promising approach to amino acids extracting from industrial enterprises wastewater is ion-exchange sorption. The plant for the sorption extraction of amino acids from wastewater includes three ion-exchange columns of vertical type, a reservoir for source water, condensate and regenerating solution tanks equipped with heating elements, and control valves system. The method of automatic control of the process of ionexchange sorption of amino acids from wastewater was developed. It includes monitoring of concentrations of waste water components, measurement of the flow rate of liquid solutions and their level in tanks. Information on the course of the process of amino acids ion-exchange sorption from wastewater is transferred from level sensors in the source water tanks, the distillate and desorption solution, the initial water acidity and when it is fed to ion exchange columns at distillate and desorbing solution temperatures, the concentration of the target component in the source water and water at the output from ion-exchange columns and flow through secondary devices to the microprocessor. Then, through the digital-to-analog converters, the correcting signal is sent to the actuators to change the performance parameters of the equipment depending on the selected criteria. Additional measurement of modes and changing
\end{abstract}

the parameters of the equipment operation depending on the selected criteria allows to increase the accuracy of control and to minimize energy and material costs.

Keywords-methionine, lysine, sorption, ion exchange, automation

\section{INTRODUCTION}

World and domestic production of amino acids tends to grow annually $[1,2]$. This is due to the intensive development of the livestock sector and its fodder production. According to experts, the market for amino acids in Russia varies between 140-145 thousand tons per year. The prevailing market share of amino acids is formed by lysine $(58 \%)$ and methionine $(28 \%)$.

Lysine is produced by microbiological synthesis [1, 2]. Methionine metabolism, unlike other amino acids, is not stereospecific; therefore, it is produced predominantly by chemical synthesis from propylene [3]. Among other chemical methods for producing propylene, 5( $\beta$-methylmercaptoethyl) 
hydantoin is used, and its hydrolysis is carried out in an aqueous alkaline medium. Hydrolysis proceeds at elevated temperature and pressure [3]. As a source for methionine production, protein hydrolysates, for example, feather keratin, are used less often or microbiological synthesis is carried out $[4,5]$.

Extraction of amino acids from industrial solutions can be effectively realized by using ion exchangers [6-8]. In this case, the choice of an ion exchanger is associated with the development of a method for extracting an amino acid based on the study of the dynamic patterns of sorption and desorption, depending on a number of factors. These include: the shape of the ion exchanger, the degree of its granulation and cross-linking; parameters of ion-exchange columns; flow rate and temperature of working solutions; efficiency of the eluent. The selectivity of the sorption of amino acids, in particular methionine, is affected by $\mathrm{pH}$, ionic strength, structural forms of ion exchangers.

Thus, to increase the efficiency of extraction of amino acids from industrial solutions, it is necessary to solve two related problems: first, the development of parameters and conditions for the sorption extraction of amino acids as objects with deterministic chemical properties; secondly, perfection of management of processes of sorption - desorption of amino acids at industrial realization of ion-exchange technologies.

Along with the economic advantages of ion-exchange technologies using for amino acids extraction from wastewater, there are problems of their practical implementation in the conditions of industrial enterprises. They are linked both with the selection of a sorbent with the necessary selectivity, solved by experimental methods, and with rational process control in an automatic mode. To do this, it is necessary to organize a timely alternation of effective operations that ensure the extraction of target components from the water medium with minimum costs, as well as to provide for precise control and regulation of the equipment operation parameters depending on the criteria selected $[9,10$, $11]$.

The purpose of the work is the development of an automatic control system for an industrial installation for ionexchange sorption of amino acids. Methionine and lysine were chosen as amino acids, as occupying a prevailing share in the market of similar products and possessing pronounced bioprotective properties.

\section{OBJECTS AND METHODS}

The object of research is the process of sorption extraction of amino acids from industrial wastewater. The subject of the study was a method of automatic control of an installation for the sorption extraction of amino acids from industrial wastewater. As a concrete example, the improvement in the control of the plant in the ion-exchange extraction of methionine from wastewater was considered when it was prepared by chemical synthesis.
To prepare the ion exchanger KU-5 for the researches, the methods described in the [12] were used, followed by its transfer to the necessary ionic forms.

Amino acid solutions were prepared from recrystallized methionine by weight, followed by dilution. Methionine exists as cations at $\mathrm{pH}<0.2$, as anions at $\mathrm{pH}>11.3$ and in the form of bipolar ions in the range $4.2<\mathrm{pH}<7.3$ [13]. The acidity of the methionine solution was created by the addition of a solution of potassium hydroxide or hydrochloric acid and monitored on an I-130 ionomer using a chain composed of silver and glass chloride electrodes.

\section{RESULTS AND DISCUSSION}

The review of intellectual property in the field of biotechnology of lysine made it possible to identify the following directions for improving its production (Fig. 1), including the technology and technology of ion exchange during the purification phase.

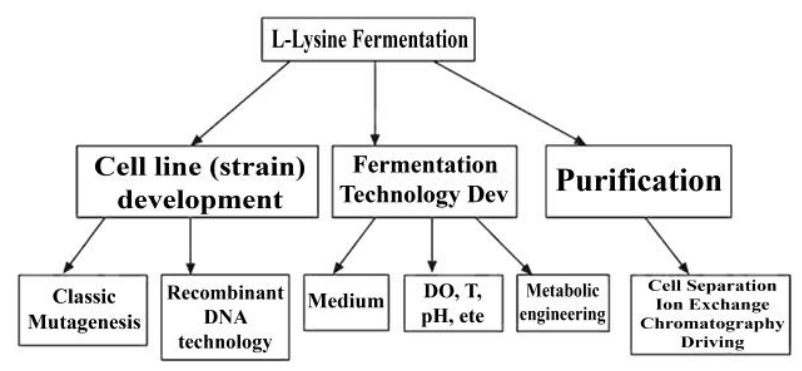

Fig. 1. Approaches to improving the production of L-lysine

Variants of industrial realization of the general scheme for the production of lysine are shown in Fig. 2. The scheme for obtaining crystalline lysine shows that the processes of sorption and desorption directly affect the yield of the purified end product [14].

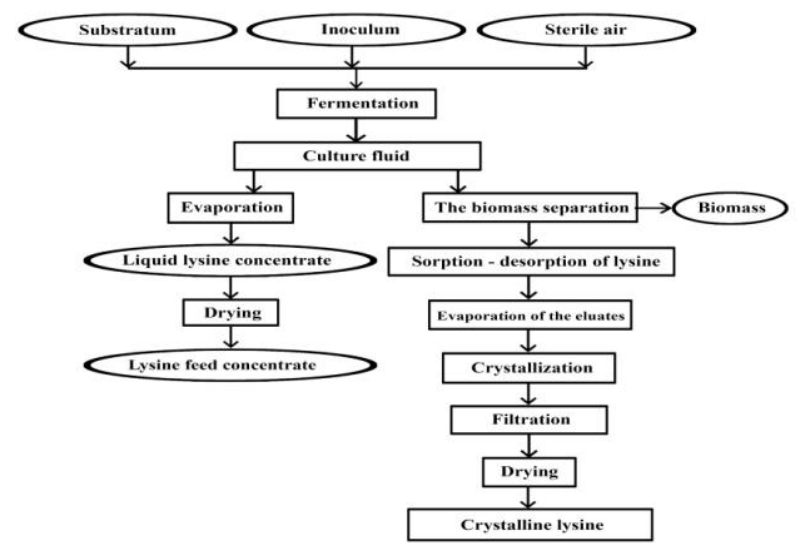

Fig. 2. A block diagram of the receiving lysine with different degrees of purification 
The scheme provides the following methods for the preparation of lysine [14]. The biomass-free solution of metabolites of the producer culture, for example, Micrococcus glutamicus with $\mathrm{pH} 7.0$, is passed through the cation exchanger in the $\mathrm{NH}^{4+}$-form. Each $100 \mathrm{~g}$ of cation exchanger is sorbed with 6-8 $\mathrm{g}$ of lysine. After washing the ion exchanger with water, lysine is desorbed with $0.5-5.0 \%$ ammonia water, the resulting solution contains $80-90 \%$ lysine from the sorbed amount.

When using the cation exchanger in the $\mathrm{H}^{+}$-form solution of the metabolites of the producer culture, it is acidified with $\mathrm{H}_{2} \mathrm{SO}_{4}$ to $\mathrm{pH}=1,6 \div 2,0$, resulting in the formation of an amino acid dicathion. After chemisorption, impurities of neutral and acidic nature are separated on the cation exchanger. The amino acids are eluted from the cation exchanger with $0.5-5 \%$ ammonium hydroxide, the solution is evaporated, acidified with $\mathrm{HCl}$ to $\mathrm{pH} 4.9 \div 5.0$, and the concentrate is crystallized at $5-12^{\circ} \mathrm{C}$. to obtain lysine monochlorohydrate crystals of light yellow or light brown color, which after the drying comprises $90-95 \%$ of the base material and $1.0-12.5 \%$ of the ash. To obtain a higher purity preparation, the purification scheme includes the step of treating the solution with active carbon, recrystallizing from $50 \%$ ethanol, which complicates the technology and increases the cost of the final product.

In general, the regularities of sorption depend on the form of existence of the amino acid in the solution: cations, anions, zwitter ions, neutral molecules. The sorption of methionine from chemical waste was investigated in work [14]. The authors found that irrespective of the ionic strength of the water-salt solution containing up to $20 \% \quad \mathrm{Na}_{2} \mathrm{SO}_{4}$ and $3 \%$ methionine, the active forms of methionine are in the ratio shown in Fig. 3.

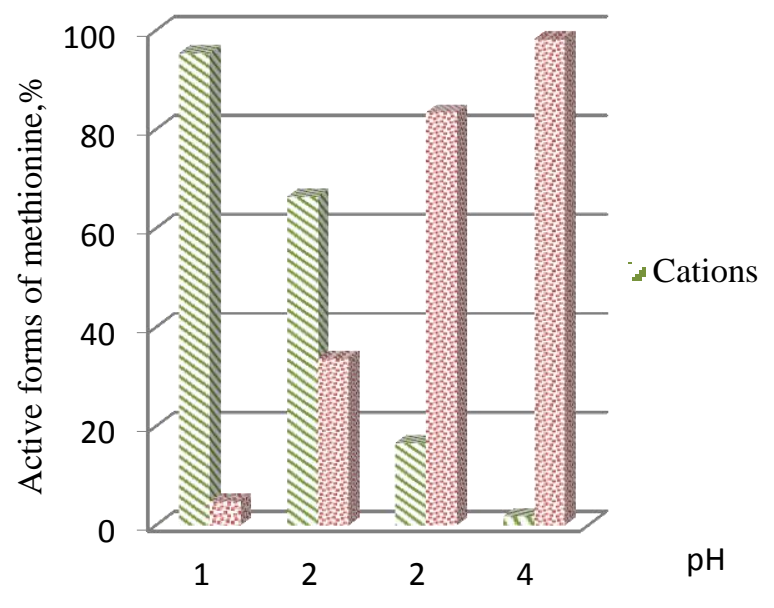

Fig. 3. Ratio of active forms of methionine

On the basis of the obtained data, the parameters of sorption extraction of methionine from sewage production waters of chemical synthesis at various $\mathrm{pH}$ parameters were determined and conditions for extraction were worked out. It was found that to efficiently extract methionine from industrial waste water, it is expedient to use KU-5 cationite in two working forms: hydrogen and sodium. It is expedient to use the hydrogen form in aqueous solutions in the $\mathrm{pH}$ range from 5.5 to 6.5 ; sodium form - in water-salt solutions in the $\mathrm{pH}$ range from 1 to 2 .

Application as an eluting solution of $\mathrm{NaOH}$ allows to completely remove methionine from the cationite sphere. A positive effect is the simultaneous regeneration of the cation exchanger. This approach provides a reduction in the volume of waste water with the repeated use of acidic solutions and alkaline eluates with a mother liquor in the technological cycles, however, in order to further improve the technology, it is advisable to apply the provisions of the theory of automatic control [11].

To assess the relevance of the problem of providing the process of methionine extraction from industrial waste water with efficient and resource-saving equipment with automated control systems, it is necessary to briefly discuss the biological role and characteristics of methionine metabolism in living systems of different levels of organization.

Methionine is a sulfur-containing essential amino acid that performs a number of unique functions in a living organism (Fig. 4)

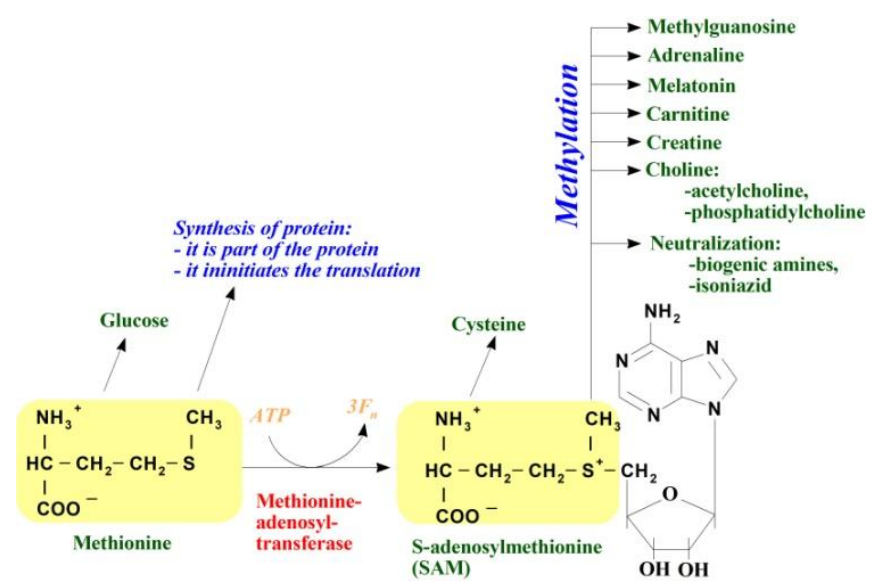

Fig. 4. Biosynthetic uses of methionine in living organism

Methionine refers to glucogenic amino acids [15]. Along with the biochemical transformations of valine, isoleucine, methionine, tryptophan, the intermediate product of their metabolism is succinyl-CoA, and the final - a high-energy substrate in the form of ATP.

Choline is a specific metabolite of methionine. Methionine, like choline, belongs to lipotropic substances. It affects the exchange of lipids and phospholipids, it is important in the prevention of atherosclerosis.

At a high level of methionine, the biological effect of vitamin $B_{12}$ and folic acid is most fully manifested. In turn, these vitamins stimulate the demethylation of methionine and the formation of choline. Methionine plays an important role in the function of the adrenal gland, it is necessary for the 
synthesis of adrenaline. There are data on the preventive effect of methionine in radiation injuries and bacterial intoxication, which supports the evaluation of it as a bioprotective component of food and feed rations.

Thus, the actual problem is an increase in the efficiency of methionine production. It is necessary to extract methionine additionally from the washing water of ion-exchange columns, represented by adsorbers of a typical design (Fig. 5), in which its residual content can be up to $7 \%$.

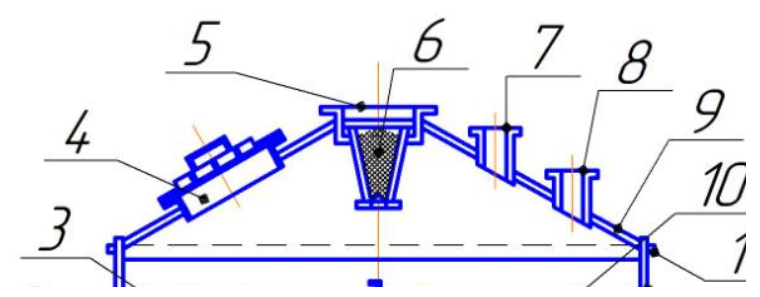

Fig. 5. Vertical adsorber: 1 - gravel; 2 - discharge opening; 3, 6 - mesh; 4 loading hatch; 5 - fitting for the filing of the original mixture, drying and cooling air through a distribution grid; 7 - fitting for vapor removal during desorption; 8 - fitting for safety valve; 9 - cover; 10 - a loads; 11 - the ring stiffness; 12 - housing; 13 - adsorbent; 14 - foot ring; 15 - grate; 16 - pipe for discharging purified gas; 17 beam; 18 - inspection hatch; 19 - fitting for condensate and feed water; 20 - bubbler; 21 - bottom; 22 - bearing beams; 23 nozzle for supplying steam through a bubbler

In the successful solution of this aspect of the problem, two stages should be distinguished: first, the improvement of the process of extracting amino acids from industrial solutions; secondly, the improvement of the control of the operation of the apparatus for the sorption extraction of amino acids, preferably in an automatic mode.

In this regard, the development of methods for waste water purification from chemical and microbiological industries, which make it possible to extract biologically valuable amino acids from them, is an actual problem of practical importance.

The scheme of the automated installation for ion-exchange sorption of amino acids from wastewater is presented in Fig. 6. The plant for ion-exchange sorption of amino acids from wastewater includes ion-exchange columns (adsorbers) of vertical type 1,2,3 source water tank 4 , containers for distillate 5 and regenerating solution 6 with heating elements, respectively 7 and 8 , control valves 9 - 26 .

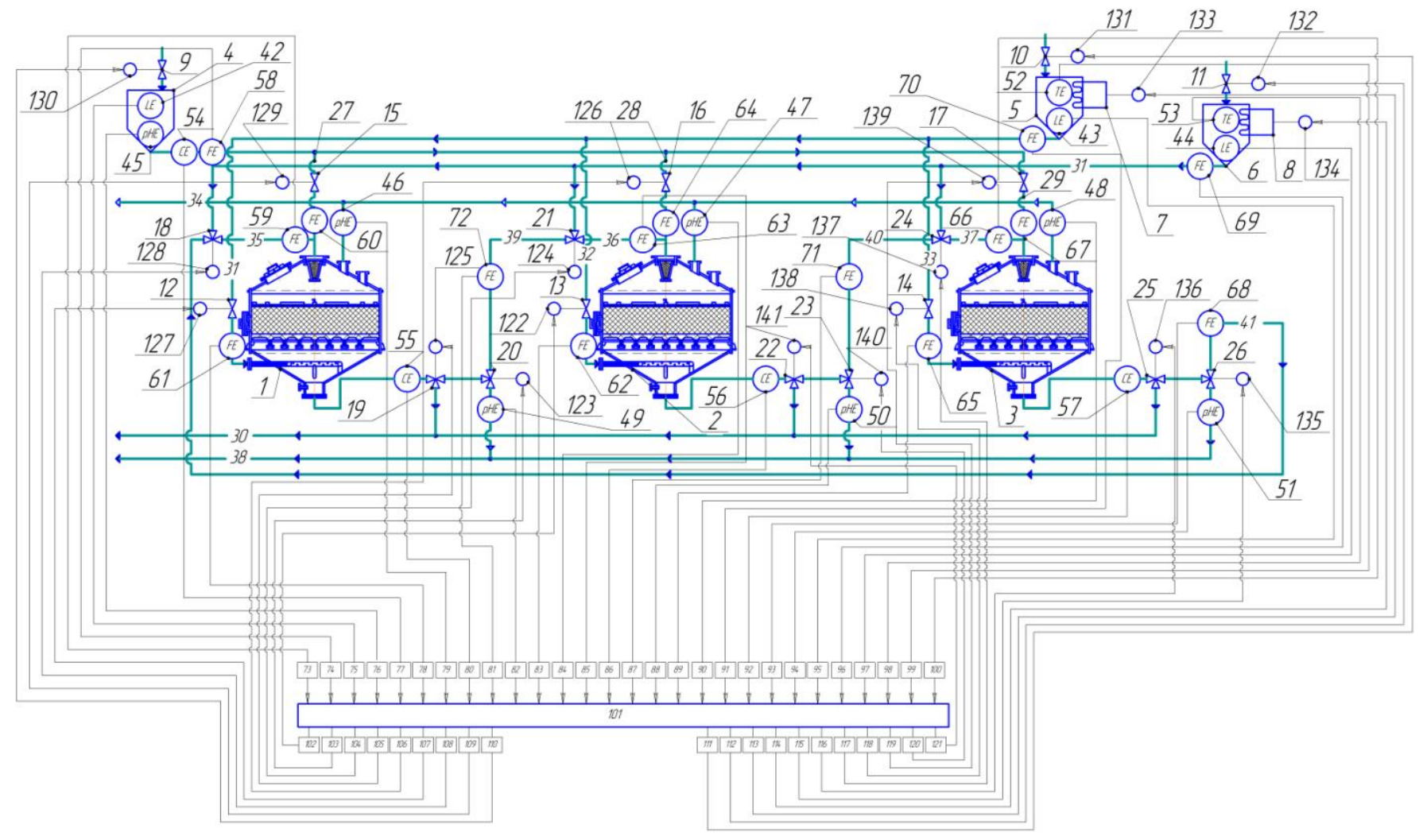

Fig. 6. Installation for ion-exchange sorption of amino acids

The scheme for the automatic control of the process of ion exchange of amino acids from wastewater also includes a source water supply line 27 to the ion exchange column 1, a feed line 28 for treating water to the ion exchange column 2, a feed water supply line 29 to the ion exchange column 3, a waste water disposal line 30 ,lines $31,32,33$ of the distillate supply to the ion exchange columns 1,2 and 3 , the distillate discharge line 34 from the ion exchange columns 1, 2 and 3, 
the regeneration solution supply lines $35,36,37$, respectively, to the ion exchange columns 1,2 and 3 , treated regenerating solution line 38 from ion-exchange columns 1, 2, 3, the partial water supply lines $39,40,41$, respectively, from the ion exchange column 1 to the ion-exchange column 2, from the ion-exchange column 2 to the ion-exchange column 3 , from the ion-exchange column 3 to the ion-exchange column 1 , level sensors 42, 43, 44, respectively, in the tanks of the source water 4 , distillate 5 and regenerating solution 6 , acidity sensors $45-51$, respectively in the source water, when fed to the ion exchange columns 1, 2 and 3, in the distillate removed from the ion exchange columns 1,2 and 3 , in the treated regenerated solution from the ion exchange columns 1,2 and 3 , the temperature sensors 52,53 , respectively the distillate in the vessel 5 and the regenerating solution in the vessel 6 , the concentration sensors of the target component 54-57, respectively, in the source water and the treated water at the outlet from the ion-exchange columns $1,2,3$, flow sensors 58-72, secondary devices 73-100, microprocessor 101, digitalto-analog converters 102-121, actuators 122-141.

The method of automatic control of the process of amino acids ion-exchange sorption from wastewater is carried out as follows.

Waste water containing the target component in the form of amino acid (for example, $20 \mathrm{~g} / 1$ of methionine), various salts (for example, $200 \mathrm{~g} / 1$ of sodium sulfate) and other components are supplied to the vessel 4, in which, by transmitting a correction signal with microprocessor 101 to the actuator 130 of the control valve 9, an allowable level of source water controlled by sensor 42 is maintained. Also in the tank 4 the required level of acidity is controlled by sensor 45 and maintained by adding the appropriate reagents (acid) (e.g., pH $1 \div 2$ ).

From the tank 4 via line 27 , the source water is fed to the ion exchange column 1 by transmitting a correction signal from the microprocessor 101 to the actuator 129 of the control valve 15 . This column is filled with a sulfocathionite having the greatest selectivity, kinetic permeability and dynamic activity with respect to the target component in the form of amino acid (for example, cationite KU-5 of polycondensation type which has the greatest selectivity for methionine upon sorption from aqueous salt solutions of wastewater).

At the same time, flow sensors 58 and 60, respectively, at the outlet of the vessel 4 and in line 27 , monitor of the flow rate of the source water, which is controlled by the transmission of a correction signal from the microprocessor 101 to the actuator 129 of the control valve 15 to provide an optimum filtration rate during sorption $30001 / \mathrm{h} \mathrm{m} 2$ ). In the ion exchange column 1, water is filtered, but when a certain residual concentration of the target component is reached in the form of amino acid (for example, equal to a methionine content of $0.5 \mathrm{~g} / 1$ ), which corresponds to a "breakthrough" point and is controlled by a target concentration sensor 55 , the next ion exchange column 2 comes into operation by directing the treated water flow from the ion exchange column 1 to the column 2 by transmitting the corrective signal from the microprocessor 101 to the actuator 125 of the regulator valve 19. In this case, the wastewater is filtered through two pre- connected columns 1 and 2. At the same time, the concentration of the target component is measured by sensors 55 and 56 in the form of amino acid (for example methionine), respectively, at the outlet of columns 1 and 2 . The wastewater is then removed via line 30 by transmitting a correction signal from the microprocessor 101 to the actuator 125 to switch the control valve 19 . When the concentration of the target component is reached as an amino acid (for example: methionine) at the outlet of column 1 controlled by sensor 55 equal to concentration at the input monitored by sensor 54 (i.e., full saturation in column 1 is observed), it is switched to the subsequent stages of displacement and desorption (i.e., to its regeneration).

To prevent contamination of desorbed methionine with sodium sulfate, the excretion of acid waste water remaining in column 1 after sorption is effected by feeding the distillate from vessel 5 with a correction signal from microprocessor 101 to actuator 127 of control valve 12. The distillate then passes through a layer of sulfocathionite in the direction opposite to sorption and at the exit from the ion exchange column 1 , the acidity is measured therein by the sensor 46 , and then it is removed through line 34 .

The distillate is fed to the ion-exchange column 1 heated in the vessel 5 to the desired temperature (for example, $70-80$ ${ }^{\circ} \mathrm{C}$ ) controlled by the sensor 52 and maintained at a predetermined level, by transmitting a correction signal from the microprocessor 101 to the actuator 132 of the heating element 7 . In the vessel 5 the required level of the distillate measured by the sensor 43 is kept with the signal from the microprocessor 101 to the actuator 131 of the control valve 10 .

After the distillate is displaced from the distillate system in the ion-exchange column 1 , a desorption solution (for example, hot $(\mathrm{t}=70 \circ \mathrm{C}) 1 \%$ sodium hydroxide solution containing 25-30 g / 1 methionine) is filtered pre-heated in the vessel 6 by sending a correction signal from the microprocessor 101 to the actuator 134 of the heating element to a predetermined temperature level (for example, 50 - 60 ${ }^{\circ} \mathrm{C}$ ). In the vessel 6 , the required level of the desorption solution measured by the sensor 44 is supported by the transmission of a correction signal from the microprocessor 101 to the actuator 132 of the control valve 11 .

The supply of the desorption solution to the ion exchange column 1 is carried out by the transfer from the microprocessor 101 to the actuator 128 of the control valve 18 .

With the help of flow sensors 69, 59 and 72, respectively, at the outlet of the tank 6 , at the inlet and outlet of the ion exchange column 1 , control over the the desorption solution consumption is made. It is controlled by the transmission of a correction signal from the microprocessor 101 to the actuator 128 of the control valve 18 to provide the optimum filtration rate for desorption (for example, $2500 \mathrm{l} / \mathrm{hr} \mathrm{m} 2$ ).

After passing of the solution through the ion exchange column 1 , it is taken as an acidic concentrated eluate at a given acidity value (for example, $\mathrm{pH}=5.5 \div 7$ ) monitored by sensor 49 and by sending a correction signal from the microprocessor 101 to the actuator 123 of the control valve 20 is removed to line 38 , from which, after cooling to room temperature, the 
crystalline target component is then extracted in the form of amino acid (for example, methionine in the amount of $75 \div$ $80 \%$ of the sorbed component).

The replacement of the regenerating solution is carried out by the transmission of corrective signals from the microprocessor 101 to the actuator 127 of the control valve 12 for the distillate supplying to the ion exchange column 1 .

At the end of the displacement of the neutral target component (for example, methionine), the eluate $\mathrm{pH}$ increases sharply and quickly reaches the initial value (for example, $\mathrm{pH}$ $=12 \div 12.5$ ). For example, the remaining methionine is desorbed in the form of methionate and, together with the mother liquor obtained by crystalline methionine filtration is used for desorption in the next cycle. Simultaneously with desorption, methionine regeneration is carried out (transfer to the sodium form). The purity of the isolated crystalline methionine is characterized by the content of the basic product and sodium sulfate (according to the specification for methionine), as well as the data obtained by elemental analysis of the product for the content of carbon, sulfur and nitrogen.

Simultaneously, after the column 1 is switched to regeneration, the source water is supplied via line 28 to the next ion-exchange column 2 , and at the same time, through the flow sensors 58 and 64, respectively, at the outlet of the vessel 4 and in the line 28, control of its flow rate which is controlled by the actuator 126 and valve 16 is produced.

Filtration in the ion exchange column 2 is also carried out before a certain residual concentration of the target component in the form of amino acid (eg, equal to a methionine content of $0.5 \mathrm{~g} / \mathrm{l})$ in water is reached in the water, which corresponds to the "breakthrough" point and controlled by the concentration sensor of the target component 56, the ion exchange column 3 is switched on by directing the treated water flow from the ion exchange column 2 to the column 3 by means of an actuator 141 and control valve 22 . Waste water, as in the first case, is also filtered through two pre-connected columns 2 and 3. At the same time, the concentration of the target component in the form of amino acid (for example, methionine) is measured by sensors 56 and 57 respectively at the outlet of columns 2 and 3 . In this case, waste water is removed via line 30 by switching valve 22 by actuator 141 . When the concentration of the target component is reached as amino acid (for example, methionine) at the outlet of column 2 equal to the concentration at the inlet (total saturation), respectively controlled by target concentrartion sensors 56 and 54, it is switched to the subsequent stages of displacement and desorption (i.e., regeneration).

The displacement of acid waste water remaining in column 2 after sorption is carried out by feeding the distillate from vessel 5 heated to the desired temperature (for example, 70 $80{ }^{\circ} \mathrm{C}$ ) controlled by sensor 52 , by transmitting a correction signal from microprocessor 101 to actuator 122 of the regulating valve 13 . At the outlet of the ion exchange column 2 , the acidity is measured in the distillate using sensor 47 , and then it is removed via line 34 .

After displacement from the distillate system, a desorption solution (for example, hot $\left(\mathrm{t}=70{ }^{\circ} \mathrm{C}\right.$ ) $1 \%$ sodium hydroxide solution containing 25-30 g / 1 methionine) preheated in vessel 6 to a predetermined temperature level (for example, 50-60 ${ }^{\circ} \mathrm{C}$ ) is filtered in ion exchange column 2 .

The desorption solution feeding to the ion exchange column 2 is carried out by transfer from the microprocessor 101 to the actuator 124 of the control valve 21 .

With the help of the flow sensors 69, 63 and 71 respectively at the outlet of the container 6 , at the inlet and outlet of the ion exchange column 2, the flow of the desorption solution is controlled, which is regulated by the transmission of the correction signal from the microprocessor 101 to the actuator 124 of the control valve 21 , for ensuring the optimum filtration rate during desorption (for example, $2500 \mathrm{l} / \mathrm{h} \mathrm{m}^{2}$ ).

After passing the solution through the ion exchange column 2 , it is taken as an acidic concentrated eluate at a given acidity value (for example, $\mathrm{pH}=5.5 \div 7$ ) controlled by the sensor 50, and by sending the correction signal from the microprocessor 101 to the actuator 140 of the control valve 23 and removed to line 38. The desorption stage is stopped when the acidity of the initial value is reached, after which the regenerating solution is displaced with a distillate.

The displacement of the regenerating solution by the distillate is effected by the transmission of corrective signals from the microprocessor 101 to the actuator 122 of the control valve 13 for supplying a distillate to the ion exchange column 2.

Simultaneously, after the column 2 is switched to regeneration, the source water is fed via line 29 to the next ion exchange column 3, and with flow sensors 58 and 67 respectively at the outlet of the vessel 4 and in line 29 this water flow is monitored, which is controlled by an actuator 141 and valve 17.

Filtration in the ion exchange column 3 is also carried out until a certain residual concentration of the target component in the form of amino acid (for example, equal to a methionine content of $0.5 \mathrm{~g} / \mathrm{l}$ ) in water is reached, which corresponds to the "breakthrough" point and controlled by the concentration sensor of the target component 57, after which the ion exchange column 1 comes into action, in which the displacement and desorption stages have passed (i.e., the process of its regeneration).

The treated water flow from the ion exchange column 3 is sent to the column 1 by transmitting a correction signal from the microprocessor 101 to the actuator 136 of the control valve 25 . The wastewater is filtered through two connected columns 3 and 1 . At the same time, the target concentration sensors 57 and 55 component in the form of an amino acid (for example, methionine), respectively, at the outlet of columns 3 and 1. At the same time, the concentration of the target component in the form of amino acid (for example, methionine) is measured by sensors 57 and 55 respectively, at the outlet of columns 3 and 1 . In this case, the waste water is removed via line 30 by transmitting a correction signal from the microprocessor 101 to the actuator 136 of the control valve 25 . Upon reaching the concentration of the target component in the form of amino acid (for example, methionine) at the outlet of column 3 equal 
to the concentration at the inlet (total saturation), respectively controlled by the sensors 57 and 54, it is switched to subsequent displacement and desorption stages (i.e. regeneration).

The displacement of the acid waste water remaining in the column 3 after sorption is carried out by feeding the distillate from vessel 5 heated to the desired temperature (for example, $70-80{ }^{\circ} \mathrm{C}$ ) controlled by the sensor 52 , by transmitting a correction signal from the microprocessor 101 to the actuator 138 of the control valve 14 . At the outlet of the ion exchange column 3 , the acidity is measured in the distillate using sensor 48, which is then removed via line 34 .

After displacement from the distillate system, a desorption solution (for example, hot $\left(\mathrm{t}=60-70{ }^{\circ} \mathrm{C}\right) 1 \%$ sodium hydroxide solution containing 25-30 g/l methionine) preheated in vessel 6 to a predetermined temperature level (for example, $70-80{ }^{\circ} \mathrm{C}$ ) is filtered in the ion exchange column 3 .

The feeding of the desorption solution to the ion exchange column 3 is effected by transfer from the microprocessor 101 to the actuator 137 of the control valve 24 .

With the help of flow sensors 69,66 and 68 respectively at the outlet of the container 6 , at the inlet and outlet of the ion exchange column 3 , the control of the consumption of the desorption solution is made. It is controlled by the transmission of a correction signal from the microprocessor 101 to the actuator 137 of the control valve 24 , for ensuring the optimum filtration rate during desorption (for example, $25001 / \mathrm{h} \mathrm{m}^{2}$ ).

After the solution passing through the ion exchange column 3 , it is taken as an acidic concentrated eluate at a given acidity value (for example, $\mathrm{pH}=5.5 \div 7$ ) controlled by the sensor 51 and by sending the correction signal from the microprocessor 101 to the actuator 135 of the control valve 26 it is removed to line 38 .

The desorption stage is stopped when the acidity of the initial value is reached, after which the regenerating solution is displaced by distillate.

The displacement of the regenerating solution with the distillate is carried out by the transmission of corrective signals from the microprocessor 101 to the actuator 138 of the control valve 14 for feeding the distillate into ion exchange column 3.

Thus, the continuous scheme of operation of ion-exchange columns 1, 2, 3 provides that when the methionine concentration reaches $0.5 \mathrm{~g} / 1$ at the outlet of the adsorber 1 , a second adsorber is connected to it, etc. In turn, the fully saturated ion exchange columns are switched to the subsequent stages of displacement and desorption, i. e. each separate adsorber operates in a closed cycle: sorption displacement of acid waste water - desorption and activation of the cationite exchanger - displacement of the regenerating solution - sorption, etc.

At the same time, the information on the course of ion exchange processes of amino acids from wastewater is transmitted from the sensors through the secondary devices 73-100 to the microprocessor 101, which provides corrective signals through the digital-to-analog converters 102-121 to the actuators 122-141 for changing the equipment operation parameters depending on the criteria chosen.

In comparison with the analogues the proposed method of automatic control of the process of ion-exchange sorption of amino acids from wastewater has some advantages. The additional measurement of the modes and changing the parameters of the equipment operation depending on the selected criteria makes it possible to improve the accuracy of control and to minimize energy and material costs [16-17]. The proposed method for controlling the plant for the sorption of amino acids is also applicable for increasing the efficiency of the extraction of lysine from a culture liquid containing lysine as a metabolite when it is produced by microbiological synthesis. A prerequisite is the adjustment of the adjustable parameters of the plant for the sorption extraction of amino acids in accordance with the chemical characteristics and sorption properties of lysine in the sorbent-sorbate system.

\section{References}

[1] S.G. Anastassiadis "L-Lysine Fermentation" Recent Patents on Biotechnology, 1(1), pp.11-24, February 2007.

[2] H. Rastegari1, M. Chiani, A. Akbarzadeh, S. C., Z. Saffari, M. R. Mehrabi, A. Farhangi, S. "Ghassemi Improvement in the Production of L-Lysine by Over- expression of Aspartokinase (ASK) in C. glutamicum ATCC 21799" Tropical J. of Pharm. Research, Vol.12(1), pp. 51-56, February 2013.

[3] V.F. Vorzhev, A.I. Shtan'kov, N.M. Stekol'nikova Ju.A., N.I. Gljancev, Ju.E. Mamontova, B.A. Sotnikov "Methionine sorption from chemical synthesis waste“, Sorpt. and chromatog. proc., T. vol. 7/6, pp.10121016, 2007.

[4] T. Willke "Methionine production - a critical review" Appl. Microbiol. and Biotech., Vol. 98/24, pp. 9893-9914, December 2014.

[5] N.B. Tadesse, D. Rama Devi, K. Basavaiah "Facile green synthesis of Lmethionine capped magnetite nanoparticles for adsorption of pollutant Rhodamine B” J. of Molecul. Liquids vol.224, p. 63, October 2016.

[6] D.V.Ovsjannikova, L.P.Bondareva, V.F.Selemenev "The equilibrium adsorption of methionine at the carboxyl lationoamerica from the solutions of different acidity," Zhurn. fiz. Himii., Vol. 83/5, pp. 961-966. 2009.

[7] L.P. Bondareva, D.V. Ovsjannikova, V.F. Selemenev "The enthalpy of interaction of an aqueous solution of methionine to the carboxylic cation exchange resin in the copper form," Zhurn. fiz. himii. 2009. Vol. 8/6. pp. 1021-1025.

[8] Ju.E. Mamontova, T.K. Stekol'nikov, Ju.A. Stekol'nikov "Thermodynamic characteristics of ion exchange of amino acids on cation," Transactions TSTU, Vol. 19/4, pp.826-832, 2013.

[9] V.Ya. Rotach "On the alternative grounds of automatic control theory," J. of Automation and Information Sciences, Vol. 31(7-9), pp. 1-5, 1999.

[10] Y.V. Sadomtsev "Problem of static accuracy in the theory of multidimensional systems of automatic control," J. of Computer and Syst. Sc.Internat, Vol. 40/2, pp. 212-223, 2001.

[11] S.T. Antipov, N.I Gljancev, N.V. Gorbatov, S.V. Shahov, A.I. Shtan'kov "Automatic control of the process of ion-exchange sorption of amino acids from waste water of industrial enterprises," Pishhevaja promyshlennost', Vol. 7, pp. 10-13, 2009.

[12] GOST-10896-78. "Ionites. Preparation for the test," Moscow: publishing House of standards, pp.5, 1999.

[13] R. Doson "Handbook of biochemistry," Moscow: Mir, pp. 544, 1991.

[14] A.Ja. Samujlenko, I.V. Pavlenko, A.A. Raevskij, S.A. Grin', I.A. Egorov, E.N. "Andrianova Receipt and use of lysine in broiler poultry farming," Vestnik Rossijskoj akademii sel'skohozjajstvennyh nauk. Vol.4, pp. 64-66, 2012. 
[15] Ju. A. Lysikov "Amino acids in human nutrition" Experimental and clinical gastroenterology, vol 2, pp. 88-105, 2012.

[16] E.V. Grigorova, L.P. Bondareva, T.S. Kornienko, D.V. Ovsjannikova "Ion-Exchange separation of methionine from aqueous solutions of different acidity at KRF-5P " Sorbcionnye i hromatograficheskie processy, vol.10/5, 2010.
[17] A.M. Zhusupova, S.K. Barbasova, O.A. Ten "Production of lysine on the semi-synthetic medium"Eurasian J. of Appl.Biotech., Vol.2, pp.5355, 2013. 